OPEN ACCESS

Edited by:

Camillo Sherif,

Karl Landsteiner University of Health

Sciences, Austria

Reviewed by:

Julie G. Pilitsis,

Albany Medical College, United States

Claudia Angelica Covarrubias,

McGill University, Canada

${ }^{*}$ Correspondence:

Hayden Scott

hscott@uams.edu

Specialty section

This article was submitted to Neurosurgery,

a section of the journal

Frontiers in Surgery

Received: 01 November 2021 Accepted: 30 December 2021

Published: 18 February 2022

Citation:

Scott H, Griffin C, Coggins W, Elberson B, Abdeldayem M, Virmani T, Larson-Prior LJ and Petersen E (2022)

Virtual Reality in the Neurosciences:

Current Practice and Future

Directions. Front. Surg. 8:807195.

doi: 10.3389/fsurg.2021.807195

\section{Virtual Reality in the Neurosciences: Current Practice and Future Directions}

\author{
Hayden Scott ${ }^{*}$, Connor Griffin ${ }^{1}$, William Coggins ${ }^{2}$, Brooke Elberson ${ }^{2}$, \\ Mohamed Abdeldayem ${ }^{3}$, Tuhin Virmani ${ }^{4}$, Linda J. Larson-Prior ${ }^{4,5,6,7,8}$ and Erika Petersen ${ }^{3}$ \\ ${ }^{1}$ College of Medicine, University of Arkansas for Medical Sciences, Little Rock, AR, United States, ${ }^{2}$ Department of \\ Neurosurgery, University of Arkansas for Medical Sciences, Little Rock, AR, United States, ${ }^{3}$ Department of Anesthesiology, \\ University of Arkansas for Medical Sciences, Little Rock, AR, United States, ${ }^{4}$ Department of Neurology, University of \\ Arkansas for Medical Sciences, Little Rock, AR, United States, ${ }^{5}$ Department of Biomedical Informatics, University of \\ Arkansas for Medical Sciences, Little Rock, AR, United States, ${ }^{6}$ Department of Pediatrics, University of Arkansas for Medical \\ Sciences, Little Rock, AR, United States, ${ }^{7}$ Department of Psychiatry, University of Arkansas for Medical Sciences, Little Rock, \\ AR, United States, ${ }^{8}$ Department of Neurobiology and Developmental Sciences, University of Arkansas for Medical Sciences, \\ Little Rock, AR, United States
}

Virtual reality has made numerous advancements in recent years and is used with increasing frequency for education, diversion, and distraction. Beginning several years ago as a device that produced an image with only a few pixels, virtual reality is now able to generate detailed, three-dimensional, and interactive images. Furthermore, these images can be used to provide quantitative data when acting as a simulator or a rehabilitation device. In this article, we aim to draw attention to these areas, as well as highlight the current settings in which virtual reality (VR) is being actively studied and implemented within the field of neurosurgery and the neurosciences. Additionally, we discuss the current limitations of the applications of virtual reality within various settings. This article includes areas in which virtual reality has been used in applications both inside and outside of the operating room, such as pain control, patient education and counseling, and rehabilitation. Virtual reality's utility in neurosurgery and the neurosciences is widely growing, and its use is quickly becoming an integral part of patient care, surgical training, operative planning, navigation, and rehabilitation.

Keywords: virtual reality, augmented reality, neurosurgery, artificial intelligence, neuroscience

\section{INTRODUCTION}

In 1939 the view-master, a simple non-electric handheld device that created a three-dimensional environment from a slide, became the first patented virtual reality device in the United States (1). Today, virtual reality (VR) has progressed from the 1900s simplistic slide display to an innovative wearable device that generates a three-dimensional environment able to be manipulated by the user in a seemingly real or physical way $(2,3)$. As such, VR has expanded into a multibilliondollar industry led by technology giants such as Facebook, Sony, and Microsoft (4). Though it has primarily been used for entertainment, the implementation of VR in medicine has been explored for the past 25 years $(1,4)$. Specifically within neurological surgery and the neurosciences, VR has been widely applied to improve peri-operative planning, surgical training, and rehabilitation $(2,3)$. 
While VR systems such as the Oculus Quest 2 (Facebook Inc., USA) and the HTC VIVE (HTC, Taiwan) produce an immersive environment simulated by a head-mounted display (HMD), augmented reality (AR) involves the superimposition of elements from virtual reality to the real-world environment in the form of holograms or videos $(2,3)$. We will focus this review on VR applications. Haptic devices provide proprioceptive, vestibular, kinesthetic, or tactile sensory information from the simulated environment to the user, and additionally are often paired with VR devices to increase their utility and provide further user immersion (5). Alongside advances in the combined use of VR with haptic devices, a multitude of different software has also been created to specialize in surgical planning, training, and rehabilitation (5). Our review aims to encompass the past, present, and future applications of VR devices in the field of neurosurgery and the neurosciences regarding medical education, skills training, patient counseling, pain management, rehabilitation, and management of neuropsychiatric disorders. To conclude, we will discuss the obstacles and limitations necessary to successfully unlock the potential of further implementing the use of virtual reality within the field of neurosurgery and the neurosciences.

\section{METHODS}

The primary literature search was performed by querying the PubMed database to identify literature published addressing the implementation of virtual reality in neurosurgery and the neurosciences. In order to search both MeSH terms and words utilized in the abstract/text, PubMed was queried using "Neurosurgery" OR "Neurosurgical Procedures" OR "Neurosciences" OR "neurosurgery OR neuroscience OR neurosurgical" AND "Virtual Reality" OR "virtual reality" with an English language only and 2010-2021 date restriction. We subsequently performed a secondary search to include the term "augmented reality" in order to fully encompass the scope of our review. Studies that evaluated the use of virtual reality in neurosurgery or the neurosciences were included in this review. Three authors (HS, CG, and WC) independently screened the articles from the literature search and created a list of studies meeting the inclusion and exclusion criteria. Articles were excluded if they were duplicates, systematic reviews, metaanalyses, commentaries, letters to the editor, or outside the scope of the topic in question (Figure 1). Articles were categorized by field and applications of virtual reality (Table 1). The list was reviewed for discrepancies by all parties and any discrepancies were settled by discussion.

\section{APPLICATIONS OF VR AS A NEUROSURGICAL SKILLS TRAINING TOOL}

To initiate our discussion regarding VR in neurosurgery and the neurosciences, it is fundamental to discuss VR's use as an integral teaching supplement and powerful means for simulating procedures. Due to the complex bony architecture of the skull, the application of VR in neurosurgical education has garnered a large amount of attention to aid in developing a comprehensive understanding of neuroanatomy and in practicing surgical skills (2, 5-12). VR models have been shown to be comparable to a cadaver and an atlas in teaching skull-based anatomy (11). Additionally, these models provide reliable localization of key anatomical landmarks in teaching craniofacial trauma when compared to computed tomography (CT) scans and can accurately simulate anatomical features of such structures as the suboccipital vertebral arteries and their surrounding bony architecture in comparison to cadaveric heads $(13,14)$. Furthermore, VR has been successfully employed to generate three-dimensional models of the sphenoid sinus (15), the clivus (16), and temporal bone (17) for teaching complex neuroanatomy. While the teaching applications involved virtual models, VR has also been utilized as a teaching resource through 360-degree videos of surgical approaches and neurological pathologies (18-22). These 360degree video procedures include: combined petrosectomy (18), arteriovenous malformation resection (19), structural changes in the brain of a person with corticobasal syndrome, (20) expanded endoscopic endonasal transtuberculum approach for tuberculum sellae meningioma (21), and immersive tutorials in specialized areas such as trauma training (22). These 360-degree videos provide a unique resource for medical students and residents to prepare for, and review, specific cases and enhance their operative education.

The ability of VR to augment traditional teaching methods is increasingly important considering the decreased supply and increased costs of cadaveric specimens $(23,24)$. The cost-benefit ratio of a VR system that can not only be used multiple times compared to a time-limited cadaver, but also can be used by students around the world, demonstrating benefits of VR. Furthermore, VR has the potential to supplement traditional training methods in the acquisition of fine motor skills for microsurgical procedures (23-28). Neurosurgical simulators in ventriculostomy have already been shown to compliment neurosurgical resident education, Cohen et al. (27), Hooten et al. (29), Schirmer et al. (30), and Haji et al. (31) and include patientspecific scenarios for an endoscopic third ventriculostomy (25). In the realm of spine surgery, VR simulators have been utilized for training in multiple varied surgeries and approaches (3235 ). In one study, two groups of senior medical students placed pedicle screws in lumbar sawbones models. One group was trained using the ImmersiveTouch simulator (ImmersiveTouch, USA) and the control group underwent traditional visual and verbal instruction. The students who were trained with a VR simulator outperformed the control group in all measures (35). Although the sample size in this study was very small (26 students were divided into two groups), despite the study population not having as advanced training as practicing neurosurgery residents or attending physicians, potential benefits of training with VR were found. VR simulators have also been applied to training in tumor resection $(36,37)$, endoscopic nasal surgeries $(28,38)$, and cerebral aneurysm clipping (39-45). Notably, with the decreased number of cerebral aneurysms treated surgically, VR simulators serve as a valuable tool for early residents to 


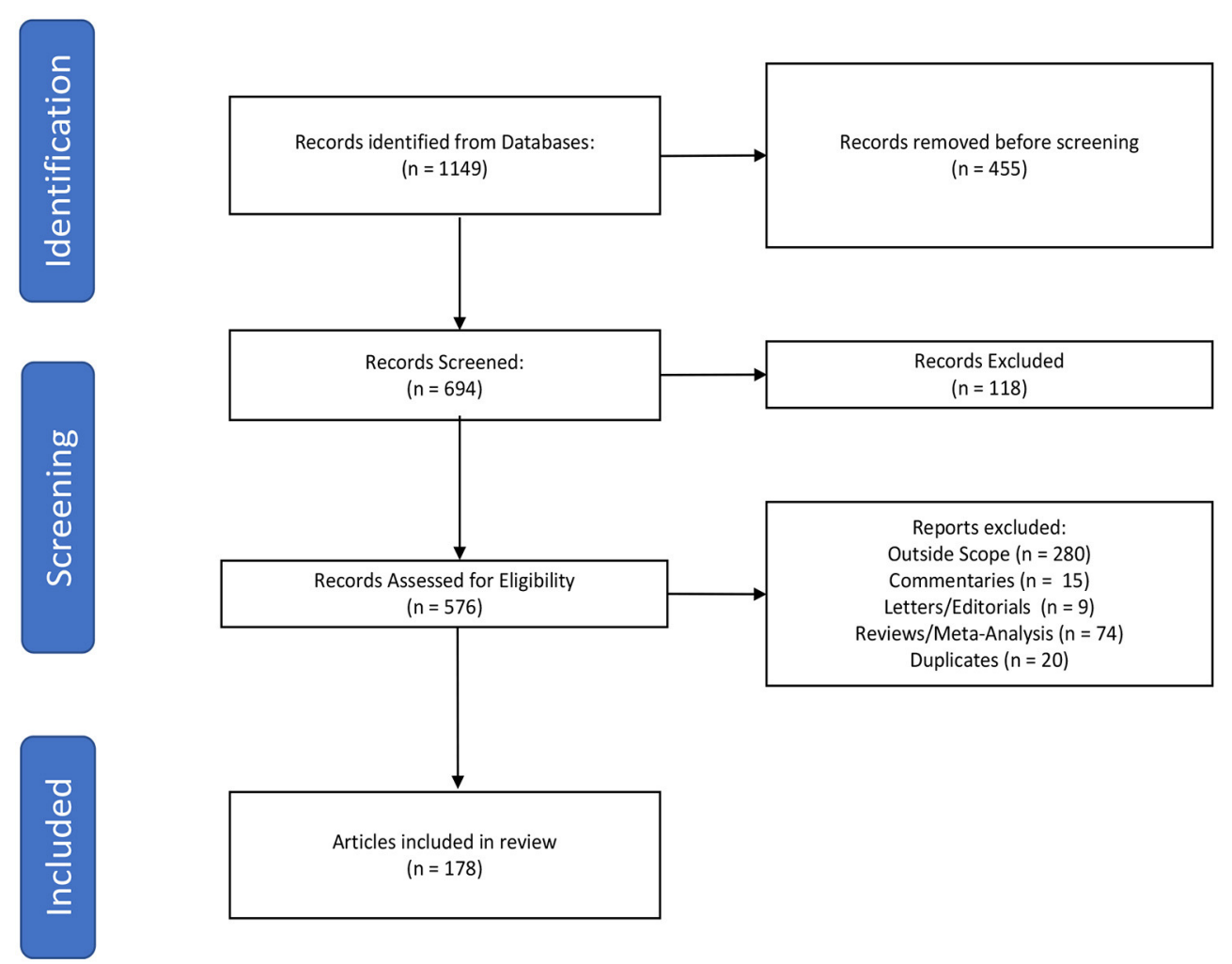

FIGURE 1 | Flowchart demonstrating identification, screening, and inclusion of articles.

TABLE 1 | Breakdown of the number of articles referenced in each section.

\begin{tabular}{lc}
\hline Topic & Number of selected articles \\
\hline Background & 5 \\
Neurosurgical training & 51 \\
Patient education/counseling & 2 \\
Distraction for awake surgery & 2 \\
Beyond the OR & 21 \\
Pain management & 10 \\
Neuropsychiatric conditions & 39 \\
Rehabilitation indications & 56 \\
Discussion & 8
\end{tabular}

Some articles are referenced in multiple sections.

practice specific approaches and techniques and improve their procedure time prior to entering the operating room $(39-43,45)$. Overall, the implementation of simulators as a foundational part of neurosurgical training contributes to an improvement in psychomotor surgical skills, safety, and cost for neurosurgical training $(9,46,47)$.

While VR simulators provide enhanced neurosurgical resident training, simulations also create large data sets (48). The data may then be analyzed to quantify psychomotor skills in neurosurgical training (48-54). When paired with artificial intelligence (AI), links are created between medicine, computer science, and education that can collaboratively revolutionize surgical training (52). The utility of AI to assess psychomotor skills is still formative but has been shown to classify individuals into different expertise levels with an accuracy of over $90 \%$ (48-52). By providing a new tool to classify surgical skills training, a shift in the longstanding paradigm of case volume being correlated with skill level could revolutionize the means in which residents are trained. With further improvements in devices and computer science, psychomotor assessment through VR simulators may become an integral component of neurosurgical education.

\section{APPLICATIONS OF VR IN NEUROSURGICAL PATIENT EDUCATION AND AS A COUNSELING TOOL}

Patient education is a cornerstone of medicine. Abiding by the principle of autonomy, each patient should be made fully aware of their medical conditions and understand the available treatment options. Oftentimes neurosurgical procedures are some of the most detailed and complex within surgery, resulting in a large knowledge gap between patient and provider. In an attempt to remedy this gap, some providers have implemented VR technology to educate and counsel their patients on treatment options. For example, Perin et al. (55) showed the educational 
benefits of VR for patients undergoing surgical removal of intracranial tumors. Patients who underwent an immersive threedimensional informed consent process involving two surgical planners displayed a higher level of objective comprehension when compared to the patient control group where patients underwent an informed consent process supported by traditional $2 \mathrm{D}$ radiological images (55).

Outside of the operating room, VR has also been implemented for patient education and counseling in a clinical setting by engaging patients in interventions that promote overall wellbeing through behavioral reinforcement and individualized educational approaches (56). The increasing number of individuals affected by chronic health conditions such as addiction, obesity, and diabetes make it imperative to provide patient education that allows individuals to observe their behaviors and review the steps required to better control these conditions. Discussing the potential changes with these patients through a non-judgmental means allows for the development and continuation of the fiduciary patient-physician relationship.

\section{APPLICATIONS OF VR FOR IMMERSIVE DISTRACTION DURING AWAKE SURGERY}

Surgical treatment can be emotionally challenging for patients, especially patients that require neurosurgical intervention. Requiring brain or spine surgery commonly represents a lifealtering event that oftentimes can lead to anxiety and distress in patients. A sincere surgeon-patient relationship remains crucial when patients are experiencing these intimidating situations. It is imperative to ensure that each patient has a full understanding of the recommended procedure. Surgeries are increasingly performed under monitored anesthesia care or, more rarely, without anesthesia other than Tylenol to reduce the chance of post-operative deficit or to improve the likelihood of a successful surgical outcome, such as precise position of a spinal cord stimulator. For example, awake craniotomies are commonly performed for patients that are affected by intractable epilepsy as well as patients undergoing tumor removal. During these procedures, the patient must be conscious during critical portions of the operation so that the surgeon remains able to monitor functions controlled by eloquent areas of the brain in close proximity to the operative field (57). VR technology has been implemented as a way to immerse patients in a simulated environment that mimics the operating room during neurosurgical procedures in order for them to develop and practice coping mechanisms (58). Additionally, there is potential to parallel this idea by using VR to immerse patients in simulated environments that distract them from the physical environment of the operating room while undergoing neurosurgical procedures.

\section{APPLICATIONS OF VR IN THE OPERATING ROOM AND BEYOND}

The same advantages that VR provides to surgical education in its ability to recreate three-dimensional anatomically precise models make it attractive for preoperational planning in neurosurgery. For example, as opposed to traditional two-dimensional magnetic resonance imaging (MRI) and computer tomography (CT) images, three-dimensional images created using virtual reality enabled neurosurgeons to study tumor-related anatomy more effectively in anterior skull base and parasagittal meningioma surgeries (21, 59-62). Virtual reality-driven $3 \mathrm{D}$ reconstruction navigation has also shown improvements over traditional image modalities in craniofacial, sellar, and infratentorial tumor resection, as well as temporomandibular joint arthroplasty surgeries (63-66). Additionally, virtual reality models provide the capability to describe orientation and shapes in which traditional imaging techniques lacked, for example areas used in microsurgical approaches such as the foramen of Monro (67).

Virtual reality images have also been shown to improve cerebrovascular surgeries by improving aneurysm detection, surgical planning, and the ability to simulate the procedure in virtual reality $(68,69)$. With regards to trauma, virtual reality appears to be as accurate as neuronavigation in planning minimally invasive cranial procedures (70). Virtual reality also shows excellent potential in planning approaches to deep brain structures such as the third ventricle and improved freehand external ventricle drain placement $(71,72)$.

Virtual reality provides a unique precise surgical model that allows the surgeon to simulate and detect structures such as a fistula in spontaneous cerebrospinal otorrhea, which traditional imaging modalities failed to identify (73). VR has been used to visualize the associated vasculature prior to hemangioblastoma resection at the craniocervical junction and is useful in planning microvascular decompression at the cerebellopontine angle (74, 75). Furthermore, virtual reality has been shown to improve surgical planning of minimally invasive spine surgeries such as spinal decompression and fusion with comparable accuracy and far less intra-operative radiation $(76,77)$. In addition, virtual reality is also being used as an imaging modality in the evaluation of post-surgical results in procedures such as monosegmental cervical fusion instead of traditional imaging modalities by measuring the smallest cross-sectional area of the intervertebral neuroforamen in the lateral resection region (78). Altogether, these areas highlight the potential for VR being utilized in every stage of an operation, including its surgical planning, surgical guidance, patient anxiety relief, and evaluation of postsurgical results.

\section{APPLICATIONS OF VR FOR ACUTE AND CHRONIC PAIN MANAGEMENT}

VR technology has been implemented in many scenarios involving the assessment and management of patients with acute and chronic pain (79). Similar to the VR application for distraction during awake neurosurgery, VR has been applied to create a distracting virtual environment for patients with acute pain. For example, when acting as a supplement to standard analgesic therapy, VR distraction decreased subjective pain ratings for worst pain intensity, pain unpleasantness, and 
time spent thinking about pain (80). Another study involving virtual waiting environments for pain distraction in patients with chronic migraines discussed the effect of VR on laser evoked potential (LEP) vertex and laser-pain ratings in patients (81). The study demonstrates that patients immersed within an ideal virtual waiting area had significantly decreased subjective pain ratings compared to those who had a virtual waiting area depicting a typical hospital waiting environment. However, a study using VR for patients with chronic neck and back pain showed no significant difference in pain intensity in individuals using VR when compared to patients carrying out physical neck exercises $(82,83)$. The lack of significant results in the latter study could be due the study being under-powered due to loss of participants to follow up. These studies lay a groundwork for future studies to build upon in order to create immersive virtual environments that successfully provide pain relief for patients in the acute and chronic settings by selecting appropriate sample sizes and properly matched controls to minimize confounders $(84,85)$.

In addition to the management of acute pain, studies have investigated the use of $\mathrm{VR}$ in patients with chronic back pain. In order to assess movement induced pain, electroencephalography (EEG) has been combined with VR to assess cortical activity identifying putative mechanisms, such as diminished disinhibition in prefrontal motor areas (86). Identifying the source of the pain could potentially allow for the development of more precise targets when developing pain management plans (86). One study involving patients with spinal cord injury who had chronic pain showed that VR technology provided an analgesic effect by applying asynchronous or synchronous visuotactile stimulation to a patient's back and to virtual legs on a VR display (87). Other applications in patients with chronic pain include the use of VR for the relief of neuropathic pain associated with phantom limb syndrome (88). In addition to chronic pain, conditions originating from a psychological foundation have also been targeted by applications of VR technology. Some of these conditions, including those centered around an individual's perception of their own body image, are discussed in further detail elsewhere in this paper.

\section{APPLICATIONS OF VR FOR NEUROPSYCHIATRIC CONDITIONS}

The application of VR and simulated environments has been used in the treatment of patients who have been affected by various neuropsychiatric conditions including specific and situational phobias, schizophrenia (44, 89-91), posttraumatic stress disorder, obsessive-compulsive disorder (9295), and autism spectrum disorder (96-103). VR has been used in those who experience situational anxiety, such as a fear of speaking in public, in order to create a simulated environment to assist individuals in overcoming the stress of that particular environment. In the case of specific phobias, desensitization and flooding have been commonly used methods that assist individuals overcome their fears (102, 104-109). In desensitization, patients are gradually exposed to items and scenarios that provoke a sense of fear, often beginning with a scenario as simple as imagining the particular fear. With gradual exposure, the goal is for the individual to essentially develop a tolerance to the stimulus to the point where it no longer elicits a sense of fear. On the contrary, flooding involves rapidly exposing individuals to objects or scenario to provoke a fear response in a controlled environment. The application of VR in standardized settings allows providers and patients to create a simulated environment that involves a particular fear-provoking stimulus in hopes of eliminating the fear response, resulting in eventual extinction (102, 104-109).

\section{APPLICATIONS OF VR FOR REHABILITATION INDICATIONS}

Virtual reality has been used extensively to aid in the rehabilitation of neurocognitive diseases, traumatic injuries, and cerebrovascular disorders due to its ability to recreate an immersive, interactive environment with real-time feedback. One unique area that VR is being applied is in the treatment of spatial neglect $(110,111)$. Prior to VR, one way in which spatial neglect is being treated is using prism adaptation, a system in which a mismatch occurs between the perceived position of a target and its actual position by shifting the field of vision through prismatic googles $(110,111)$. VR can replicate this process and provide enhanced blinding due to its manipulatable immersive environment $(110,111)$. VR's application in this area is of interest since the results of prism adaptation have been questionable at best (112). Nevertheless, other forms of rehabilitation for chronic neglect patients such as VR visual scanning rehabilitation programs, games in which patients actively pay attention to and interact to stimuli on their affected side, seems to induce a plasticity process that benefits chronic neglect patients $(113,114)$.

VR feedback has been paired with a gravity-compensating multi-joint exoskeleton for the upper extremities to facilitate and provide feedback in reach-to-grasp rehabilitation in stroke patients (115-117). Specifically, VR environments provide quantitative assessment of upper and lower limb movements, that can be utilized to adapt subsequent sessions thereby aiding in stroke rehabilitation (118). A randomized-controlled trial suggests that the addition of VR feedback to traditional rehabilitation of the upper limb promotes better stroke outcomes regardless of stroke etiology (119). VR walking simulators further show potential in aiding stroke patients for lower extremity rehabilitation (120). Given the potential application VR has for upper and lower extremity rehabilitation, VR rehabilitation systems grounded in neuroscience are being created to assist in the recovery of motor functions after neurologic insult $(121,122)$.

One aspect of stroke rehabilitation involves the use of multisensory modalities to improve our ability to detect and discriminate stimuli and create an optimal environment for learning (123). VR provides the ability to recreate these environments through simple tactile feedback games. Moreover, a study that combined VR with levodopa for acute stroke rehabilitation has been tested to evaluate its synergistic neuroplastic effect. While the study has limited power $(n=8)$, it did succeed in showing significant improvements in upper 
extremity kinematic function in the VR/levodopa group in comparison to the control group receiving levodopa alone (124). Other approaches paired with VR to generate this multisensory effect include the Michelangelo effect, a term coined by a study evaluating the impact of a VR program where the user creates a masterpiece when painting on a virtual canvas (125).

Because rehabilitation for chronic stroke patients continues long after the time spent in rehabilitation facilities, interest has been growing into creating VR programs for consumer headmounted displays $(126,127)$. More primitive non-immersive virtual reality systems such as the Nintendo Wii (Nintendo, Japan) have already been shown to provide sustained benefit to stroke patients $(128,129)$. As a result, the rehabilitation gaming systems (RGS) model of stroke rehabilitation has been suggested to be more effective than traditional stroke therapies (130). Additionally, VR games for post-stroke treatment appear to be beneficial in treating stroke sequelae by improving the symmetry of body temperature, balance, and functionality of stroke patients (131).

When combined with robot-assisted gait training, VR seems to be a viable alternative to traditional motor rehabilitation in patients with multiple sclerosis (MS) (132). VR's potential to use dual-task therapy for multiple sclerosis patients when paired with a treadmill is currently being studied (133). Furthermore, VR games have been used as motor tasks in MS patients to evaluate the effect of cognitive function and fatigue on motor performance improvement (134). Taken together, these studies highlight the potential role of VR in MS rehabilitation.

For spinal cord injuries, VR games have gained interest in their application for balance training. However, in one study, semi-immersive VR therapy when paired with conventional rehabilitation as opposed to traditional rehabilitation alone revealed no significant differences (135). VR does show promise in its ability to induce illusionary spinal movements that eclipse standard mirror therapy for the treatment of limb pain by amplifying small neck movements into perceived larger ones (136). VR has gained interest in treating Alzheimer's disease by inducing neuroplasticity (137) and providing gait training (138) through the pairing of multiple daily life task simulators with walking on a treadmill. Additionally, VR is being incorporated into moving platform systems to improve a patient's gait and posture (139). While VR with moving tasks in elderly patients, such as a walking on a treadmill, appears dangerous, a study suggested that for balance in the elderly these systems appear to provide the most benefit for safety and outcomes when combined with a mixed exercise (140). VR has warranted attention in the area of rehabilitation in people who experienced a traumatic brain injury. Specifically, driving VR interfaces have shown the benefits of cognitive rehabilitation of working memory to increase efficiency in neural networks $(141,142)$.

Virtual reality is also being actively used in the rehabilitation of developmental and ocular neurological diseases. For instance, VR coupled with robotic exoskeleton devices has been used to assess the motor deficits in children with fetal alcohol syndrome (143). Due to the ability of head-mounted displayed VR systems to manipulate each eye, VR systems have been developed to induce neuroplasticity in children with amblyopia (144). Within this same field of rehabilitation, a VR system involving squashing bugs was developed to rehabilitate adults suffering from loss of stereo vision, the ability to process the depth of an image using binocular vision, from conditions such as strabismus or amblyopia (145). This is of significance due to the limited number of studies documenting recovery of stereo vision in adults as opposed to children, which may pave the way for an exciting new area in rehabilitation using VR (145).

VR's ability to provide haptic feedback through reach and grasp movements in a VR environment has gained interest in rehabilitating children with mild unilateral and dystonic cerebral palsy $(146,147)$. Additionally, studies are now being designed to evaluate the combination of motor movement training through VR paired with anodal transcranial stimulation, a form of transcranial stimulation that favors cortical excitability and depolarization, in the rehabilitation of upper limb movement in children with Down syndrome (148). VR with anodal transcranial stimulation also shows promising results for improving gait in people with motor disorders such as cerebral palsy (149). VR programs have been used to test spatial learning and memory in surgery-naive temporal lobe epilepsy, which suggested the integrity of both hemispheres is critical for spatial learning and memory (150).

In the rehabilitation of Parkinson's disease patients, VR facilitated motor-imitation therapy has been shown to have many applications [for a detailed recent review see (151)]. Studies have shown VR to help reduce PD patient's hypometria (152, 153). Finger tapping testing for Parkinson's patients in a virtual environment appears to yield similar results compared to standard finger tapping testing (154) VR combined with treadmill rehabilitation shows some feasibility in improving gait by modifying brain activation patterns using optic flow, the experienced change in scenery in virtual reality by walking (155-158). To evaluate Parkinson's patients with freezing of gait (FOG), VR has been employed and suggests that Parkinson's patients with FOG show slower motor initiation, increased movement hesitation, and marked impairment of motor movement inhibition $(159,160)$. Thus, VR programs for Parkinson's patients have been created to improve movement and problem solving by completing tasks in a virtual environment (161). When paired with the Nintendo Wii, exercise appears to produce a more significant therapeutic effect for Parkinson's patients than conventional exercise alone (162). VR rehabilitation programs seem to be as effective as traditional rehabilitation yet can better determine the overall improvement due to data input from the device (163).

\section{DISCUSSION}

The rapid advancements in technology, including those involving VR devices, have led to complex technology that can only be used to their full potential if the operator has a foundational understanding of the technology being implemented (164). Once that underlying issue is overcome, the application of virtual reality poses several other obstacles that can complicate their use in the neurosciences. For example, many neurosurgical 
TABLE 2 | Summary table of findings and pathologies discussed in the referenced articles.

\begin{tabular}{lll}
\hline Topic Reference Findings & R
\end{tabular}

Neurosurgical skills and training tools

Anatomy education

360-degree education video

VR simulators

Artificial intelligence with VR

Patient education/counseling

VR during awake surgery

$V R$ in the operating room and beyond

VR imaging compared to traditional imaging

3D navigation using $V R$

VR for operation planning

\section{Acute/chronic pain management}

Acute Pain

Chronic Pain

Neuropsychiatric conditions

Schizophrenia

PTSD and OCD

Autism

Desensitization/Flooding

Rehabilitation

Spatial neglect

Stroke

Multiple Sclerosis

Spinal cord injuries

Alzheimer's disease

Gait training

Traumatic brain injury

Fetal alcohol syndrome

Amblyopia

Pediatric

Epilepsy

Parkinson's disease

\section{Discussion}

Competence in VR

(44, 89-91)

(92-95)

(96-103)

(102, 104-111)

(112-116)

(117-131)

(132-134)

$(135,136)$

(137)

(138-140)

$(141,142)$

(143)

$(144,145)$

(143, 144, 146-

149)

(150)

(151-163)

Incompatibility of VR with standard equipment

Risks of using VR

Prospective view of VR
(164)

(165)

(166-170)

(171)
Findings

(11) Anatomy teaching comparable to cadaver/atlas

(23) Apparent cost benefit of simulation training

(24) Apparent cost benefit of simulation training

(35) Simulation group outperformed control group

(55) Increased comprehension in VR group over control group

(70) Suggests VR accuracy is equal to that of neuronavigation In planning minimally invasive procedures

(76) VR utility in surgical planning and post-surgical evaluation in spinal decompression

(77) VR utility as an image modality in spinal fusion

(80): VR's utility as a supplement to standard anesthesia decreased subjective pain rating (82) Study suggested VR did not improve chronic back pain rating
(113): VR rehabilitation induces neuroplasticity over traditional rehabilitation

(114) fMRI study illustrating VR's possibility in inducing neuroplasticity for chronic neglect patients

(119) Highlights the benefits of adding VR rehabilitation in addition to traditional rehabilitation

(124) Highlights the benefit of VR with pharmacology for stroke rehabilitation

(135) VR paired with conventional spine therapy showed no significant improvement
(152) VR utility in imitation training

(153) VR utility in imitation training

(162) Older study suggesting Wii exercise provided greater therapeutic effect than conventional exercise 
procedures require intraoperative imaging, such as MRI or CT; however, the standard virtual reality devices controllers and HMDs are not compatible with MRI and implementation in such settings would require this development (165). As previously mentioned, intractable epilepsy is a common indication for neurosurgical care; however, the possibility of photosensitive seizures induced by VR devices has been discussed in the literature. Although the medical literature did not support the idea of VR resulting in photosensitive seizures, many HMD manufactures, such as Oculus, include risk of seizure in their health and safety warnings with use of their product (166). In a small study of patients with Parkinson's Disease, the use of VR has been associated with the development of visual hallucinations (167). Unwanted effects from VR immersive systems may be specific to the individuals it is used for, and a system may need to be designed according to its particular use. Another study reported participants experienced unpleasant symptoms, including nausea and disorientation, related to virtual reality sickness and effects (VRISE) (168). The maximum duration of VR immersion should be limited to between 55 and $70 \mathrm{~min}$, as longer exposure increases the probability of the occurrence and intensity of VRISE (169). VR has been adapted for use in specific medical scenarios, but it is important to highlight that patients and not the medical providers are the end users (170). Therefore, implementing the use of VR in the neurosciences should not be solely focused on the advantage to the medical providers. For the long-run, VR technology needs to be implemented in ways that are mutually beneficial to patients and physicians, thereby enhancing the patient-physician relationship. We have provided a table summarizing our findings related to the application of VR both inside and outside the operating room (Table 2). Many of these applications are novel, as the technology

\section{REFERENCES}

1. Sawyer's View-Master. National Museum of American History. Available online at: https://americanhistory.si.edu/collections/search/object/nmah_ 1129885 (accessed March 14, 2021).

2. Yeung AWK, Tosevska A, Klager E, Eibensteiner F, Laxar D, Stoyanov J, et al. Virtual and augmented reality applications in medicine: analysis of the scientific literature. J Med Internet Res. (2021) 23:e25499. doi: 10.2196/25499

3. Fiani B, De Stefano F, Kondilis A, Covarrubias C, Reier L, Sarhadi K. Virtual reality in neurosurgery: "can you see it?"-a review of the current applications and future potential. World Neurosurg. (2020) 141:291-8. doi: 10.1016/j.wneu.2020.06.066

4. Cipresso P, Giglioli IAC, Raya MA, Riva G. The past, present, and future of virtual and augmented reality research: a network and cluster analysis of the literature. Front Psychol. (2018) 9:2086. doi: 10.3389/fpsyg.2018.02086

5. Alaraj A, Lemole M, Finkle J, Yudkowsky R, Wallace A, Luciano C, et al. Virtual reality training in neurosurgery: review of current status and future applications. Surg Neurol Int. (2011) 2:52. doi: 10.4103/2152-7806.80117

6. Robison RA, Liu CY, Apuzzo MLJ. Man, mind, and machine: the past and future of virtual reality simulation in neurologic surgery. World Neurosurg. (2011) 76:419-30. doi: 10.1016/j.wneu.2011.07.008

7. Chan S, Conti F, Salisbury K, Blevins NH. Virtual reality simulation in neurosurgery: technologies and evolution. Neurosurgery. (2013) 72:154-64. doi: 10.1227/NEU.0b013e3182750d26

8. Lungu AJ, Swinkels W, Claesen L, Tu P, Egger J, Chen X. A review on the applications of virtual reality, augmented reality and mixed reality in itself is relatively novel, and delineation of proper guidelines is ongoing.

Despite the challenges ahead, VR has become a new tool widely employed across the neurosciences and neurological surgery. From rehabilitation to resident education and acute pain to intra-operative feedback, VR has integrated itself widely throughout many different specialties. As the technology surrounding virtual environments advances and the ability to incorporate haptic feedback provides further immersion to an augmented environment and feedback from said environment, VR will continue to redefine neurosurgical training and patient care. By providing a safe, superior, flexible, and readily available tool, VR has the potential to further shape the future of the neurosciences and neurosurgery. Significant advancements in neurosurgery occur every 20 years, but rapid progressions in technology can assist in transforming the field at a more rapid rate (171). Recently, Neurosurgical Focus dedicated an issue solely to virtual and augmented reality, demonstrating the impact of this technology within the field of neurosurgery. Similar to the articles we have discussed in our review, articles within this issue of Neurosurgical Focus also highlight how the implementation of virtual and augmented reality have and will continue to result in rapid advancements in operative planning, intraoperative navigation, and neurosurgical training.

\section{AUTHOR CONTRIBUTIONS}

$\mathrm{EP}, \mathrm{WC}, \mathrm{BE}$, and MA: main concept and manuscript outline. HS, CG, and WC: literature search, article screening, manuscript draft, and revision. LL-P, EP, WC, TV, BE, and MA: draft edits and commentaries. All authors reviewed article prior to submission. surgical simulation: an extension to different kinds of surgery. Expert Rev Med Devices. (2020) 18:47-62. doi: 10.1080/17434440.2021.1860750

9. Sheik-Ali S, Edgcombe H, Paton C. Next-generation virtual and augmented reality in surgical education: a narrative review. Surg Technol Int. (2019) 35:1-9.

10. Ekstrand C, Jamal A, Nguyen R, Kudryk A, Mann J, Mendez I. Immersive and interactive virtual reality to improve learning and retention of neuroanatomy in medical students: a randomized controlled study. CMAJ Open. (2018) 6:E103-9. doi: 10.9778/cmajo.20170110

11. Chen S, Zhu J, Cheng C, Pan Z, Liu L, Du J, et al. Can virtual reality improve traditional anatomy education programmes? A mixed-methods study on the use of a 3D skull model. BMC Med Educ. (2020) 20:395. doi: 10.1186/s12909-020-02255-6

12. Atli K, Selman W, Ray A. A comprehensive multicomponent neurosurgical course with use of virtual reality: modernizing the medical classroom. J Surg Educ. (2020) 78:1350-6. doi: 10.1016/j.jsurg.2020.11.003

13. Bouaoud J, El Beheiry M, Jablon E, Schouman T, Bertolus C, Picard A, et al. DIVA, a 3D virtual reality platform, improves undergraduate craniofacial trauma education. J Stomatol Oral Maxillofac Surg. (2020) 122:367-71. doi: 10.1016/j.jormas.2020.09.009

14. Ha W, Yang DL, Gu S, Xu QW, Che X, Wu JS, et al. Anatomical study of suboccipital vertebral arteries and surrounding bony structures using virtual reality technology. Med Sci Monit. (2014) 20:802-6. doi: 10.12659/MSM.890840

15. Wang S Sen, Xue L, Jing JJ, Wang RM. Virtual reality surgical anatomy of the sphenoid sinus and adjacent structures by the transnasal approach. 
J Cranio Maxillofac Surg. (2012) 40:494-9. doi: 10.1016/j.jcms.2011. 08.008

16. Wang S Sen, Li JF, Zhang SM, Jing JJ, Xue L. A virtual reality model of the clivus and surgical simulation via transoral or transnasal route. Int J Clin Exp Med. (2014) 7:3270-9.

17. Morone PJ, Shah KJ, Hendricks BK, Cohen-Gadol AA. Virtual, 3-dimensional temporal bone model and its educational value for neurosurgical trainees. World Neurosurg. (2019) 122:e1412-5. doi: 10.1016/j.wneu.2018.11.074

18. Bernard F, Troude L, Laccourreye L, Roche P-H, Fournier H-D. Stereoscopic surgical video of combined petrosectomy with virtual reality headset: 3-dimensional operative video. Operat Neurosurg. (2019) 16:638-9. doi: 10.1093/ons/opy228

19. Steinberger J, Nistal D, Schlachter L, Costa A, Oemke H, Bederson JB. A virtual-reality, 360-degree fly-through of an arteriovenous malformation resection: 2-dimensional operative video. Operat Neurosurg. (2020) 18:E11. doi: 10.1093/ons/opz062

20. Hänel C, Pieperhoff P, Hentschel B, Amunts K, Kuhlen T. Interactive 3D visualization of structural changes in the brain of a person with corticobasal syndrome. Front Neuroinform. (2014) 8:42. doi: 10.3389/fninf.2014. 00042

21. Jean WC, Singh A. Expanded endoscopic endonasal transtuberculum approach for tuberculum sellae meningioma: operative video with 360-degree fly-through and surgical rehearsal in virtual reality: 2dimensional operative video. Operat Neurosurg. (2020) 19:E179-80. doi: 10.1093/ons/opaa017

22. Patel D, Hawkins J, Chehab LZ, Martin-Tuite P, Feler J, Tan A, et al. Developing virtual reality trauma training experiences using 360-Degree video: tutorial. J Med Internet Res. (2020) 22:e22420. doi: 10.2196/ 22420

23. Oliveira L, Figueiredo E. Simulation training methods in neurological surgery. Asian J Neurosurg. (2019) 14:364. doi: 10.4103/ajns.ajns_269_18

24. Tai AX, Sack KD, Herur-Raman A, Jean WC. The benefits of limited orbitotomy on the supraorbital approach: an anatomic and morphometric study in virtual reality. Operat Neurosurg. (2020) 18:542-550. doi: 10.1093/ons/opz201

25. Armstrong R, Eagleson R, De Ribaupierre S. Patient-specific pipeline to create virtual endoscopic third ventriculostomy scenarios. Stud Health Technol Inform. (2014) 106:14-6. doi: 10.3233/978-1-61499-375-9-14

26. Jean WC, Felbaum DR. The use of augmented reality to improve safety of anterior petrosectomy: two-dimensional operative video. World Neurosurg. (2021) 146:162. doi: 10.1016/j.wneu.2020.11.054

27. Cohen AR, Lohani S, Manjila S, Natsupakpong S, Brown N, Cavusoglu MC. Virtual reality simulation: basic concepts and use in endoscopic neurosurgery training. Childs Nervous Syst. (2013) 29:1235-44. doi: 10.1007/s00381-013-2139-z

28. Varshney R, Frenkiel S, Nguyen LHP, Young M, Del Maestro R, Zeitouni A, et al. The McGill simulator for endoscopic sinus surgery (MSESS): a validation study. J Otolaryngol Head Neck Surg. (2014) 43:40. doi: 10.1186/s40463-014-0040-8

29. Hooten KG, Lister JR, Lombard G, Lizdas DE, Lampotang S, Rajon $\mathrm{DA}$, et al. Mixed reality ventriculostomy simulation: experience in neurosurgical residency. Neurosurgery. (2014) 10 Suppl 4:576-81. doi: 10.1227/NEU.0000000000000503

30. Schirmer CM, Elder JB, Roitberg B, Lobel DA. Virtual reality-based simulation training for ventriculostomy: an evidence-based approach. Neurosurgery. (2013) 73:66-73. doi: 10.1227/NEU.0000000000000074

31. Haji FA, Dubrowski A, Drake J, De Ribaupierre S. Needs assessment for simulation training in neuroendoscopy: a Canadian national survey; Clinical article. J Neurosurg. (2013) 118:250-7. doi: 10.3171/2012.10.JNS12767

32. Ledwos N, Mirchi N, Bissonnette V, Winkler-Schwartz A, Yilmaz R, Del Maestro RF. Virtual reality anterior cervical discectomy and fusion simulation on the novel sim-ortho platform: validation studies. Operat Neurosurg. (2021) 20:74-82. doi: 10.1093/ons/opaa269

33. Luca A, Giorgino R, Gesualdo L, Peretti GM, Belkhou A, Banfi $\mathrm{G}$, et al. Innovative educational pathways in spine surgery: advanced virtual reality-based training. World Neurosurg. (2020) 140:674-80. doi: 10.1016/j.wneu.2020.04.102
34. Lohre R, Wang JC, Lewandrowski KU, Goel DP. Virtual reality in spinal endoscopy: a paradigm shift in education to support spine surgeons. J Spine Surg. (2020) 6:S208-23. doi: 10.21037/jss.2019.11.16

35. Gasco J, Patel A, Ortega-Barnett J, Branch D, Desai S, Kuo YF, et al. Virtual reality spine surgery simulation: an empirical study of its usefulness. Neurol Res. (2014) 36:968-73. doi: 10.1179/1743132814Y.0000000388

36. Shao X, Yuan Q, Qian D, Ye Z, Chen G, Le Zhuang K, et al. Virtual reality technology for teaching neurosurgery of skull base tumor. BMC Med Educ. (2020) 20:3. doi: 10.1186/s12909-019-1911-5

37. Gélinas-Phaneuf N, Choudhury N, Al-Habib AR, Cabral A, Nadeau E, Mora $\mathrm{V}$, et al. Assessing performance in brain tumor resection using a novel virtual reality simulator. Int J Comput Assist Radiol Surg. (2014) 9:1-9. doi: 10.1007/s11548-013-0905-8

38. Rosseau G, Bailes J, Del Maestro R, Cabral A, Choudhury N, Comas O, et al. The Development of a virtual simulator for training neurosurgeons to perform and perfect endoscopic endonasal transsphenoidal surgery. Neurosurgery. (2013) 73:85-93. doi: 10.1227/NEU.0000000000000112

39. Alaraj A, Luciano CJ, Bailey DP, Elsenousi A, Roitberg BZ, Bernardo A, et al. Virtual reality cerebral aneurysm clipping simulation with real-time haptic feedback. Operat Neurosurg. (2015) 11:52-8. doi: 10.1227/NEU.0000000000000583

40. Beier F, Sismanidis E, Stadie A, Schmieder K, Männer R. An aneurysm clipping training module for the neurosurgical training simulator NeuroSim. Stud Health Technol Inform. (2012) 173:42-7. doi: 10.3233/978-1-61499-022-2-42

41. Agarwal N, Schmitt PJ, Sukul V, Prestigiacomo CJ. Surgical approaches to complex vascular lesions: the use of virtual reality and stereoscopic analysis as a tool for resident and student education. BMJ Case Rep. (2012) 2012:bcr0220125859. doi: 10.1136/bcr.02.2012.5859

42. Di Somma A, De Notaris M, Stagno V, Serra L, Enseñat J, Alobid I, et al. Extended endoscopic endonasal approaches for cerebral aneurysms: anatomical, virtual reality and morphometric study. Biomed Res Int. (2014) 2014:703792. doi: 10.1155/2014/703792

43. Dardick J, Allen S, Scoco A, Zampolin RL, Altschul DJ. Virtual reality simulation of neuroendovascular intervention improves procedure speed in a cohort of trainees. Surg Neurol Int. (2019) 10:184. doi: 10.25259/sni_313_2019

44. Spanlang B, Nierula B, Haffar M, Debruille JB. Mimicking Schizophrenia: Reducing P300b by Minimally Fragmenting Healthy Participants' Selves Using Immersive Virtual Reality Embodiment. Front Hum Neurosci. (2019) 12:504. doi: 10.3389/fnhum.2018.00504

45. Teodoro-Vite S, LastNamePérez-Lomelí JS, Domínguez-Velasco CF, Hernández-Valencia AF, Capurso-García MA, Padilla-Castañeda MA. A high-fidelity hybrid virtual reality simulator of aneurysm clipping repair with brain sylvian fissure exploration for vascular neurosurgery training. Simul Healthc. (2020) 16:285-94. doi: 10.1097/SIH.0000000000000489

46. Kim DH, Kim Y, Park JS, Kim SW. Virtual reality simulators for endoscopic sinus and skull base surgery: the present and future. Clin Exp Otorhinolaryngol. (2019) 12:12-17. doi: 10.21053/ceo.2018.00906

47. Baby B, Singh R, Suri A, Dhanakshirur RR, Chakraborty A, Kumar S, et al. A review of virtual reality simulators for neuroendoscopy. Neurosurg Rev. (2020) 43:1255-72. doi: 10.1007/s10143-019-01164-7

48. Winkler-Schwartz A, Bissonnette V, Mirchi N, Ponnudurai N, Yilmaz $\mathrm{R}$, Ledwos $\mathrm{N}$, et al. Artificial intelligence in medical education: best practices using machine learning to assess surgical expertise in virtual reality simulation. J Surg Educ. (2019) 76:1681-90. doi: 10.1016/j.jsurg.2019.05.015

49. Mirchi N, Bissonnette V, Yilmaz R, Ledwos N, Winkler-Schwartz A, Del Maestro RF. The virtual operative assistant: an explainable artificial intelligence tool for simulation-based training in surgery and medicine. PLoS ONE. (2020) 15:e0229596. doi: 10.1371/journal.pone.0229596

50. Bissonnette V, Mirchi N, Ledwos N, Alsidieri G, Winkler-Schwartz A, Del Maestro RF. Artificial intelligence distinguishes surgical training levels in a virtual reality spinal task. J Bone Joint Surg Am. (2019) 101:e127. doi: 10.2106/JBJS.18.01197

51. Winkler-Schwartz A, Yilmaz R, Mirchi N, Bissonnette V, Ledwos N, Siyar $S$, et al. Machine learning identification of surgical and operative factors associated with surgical expertise in virtual reality simulation. JAMA Netw Open. (2019) 2:e198363. doi: 10.1001/jamanetworkopen.2019.8363 
52. Siyar S, Azarnoush H, Rashidi S, Winkler-Schwartz A, Bissonnette V, Ponnudurai N, et al. Machine learning distinguishes neurosurgical skill levels in a virtual reality tumor resection task. Med Biol Eng Comput. (2020) 58:1357-67. doi: 10.1007/s11517-020-02155-3

53. Winkler-Schwartz A, Marwa I, Bajunaid K, Mullah M, Alotaibi FE, Bugdadi A, et al. A comparison of visual rating scales and simulated virtual reality metrics in neurosurgical training: a generalizability theory study. World Neurosurg. (2019) 127:e230-35. doi: 10.1016/j.wneu.2019.03.059

54. Mirchi N, Bissonnette V, Ledwos N, Winkler-Schwartz A, Yilmaz R, Karlik B, et al. Artificial neural networks to assess virtual reality anterior cervical discectomy performance. Operat Neurosurg. (2020) 19:65-75. doi: 10.1093/ons/opz359

55. Perin A, Galbiati TF, Ayadi R, Gambatesa E, Orena EF, Riker NI, et al. Informed consent through $3 \mathrm{D}$ virtual reality: a randomized clinical trial. Acta Neurochir. (2021) 163:301-8. doi: 10.1007/s00701-020-04303-y

56. Ershow AG, Peterson CM, Riley WT, Rizzo A, Wansink B. Virtual reality technologies for research and education in obesity and diabetes: research needs and opportunities. J Diabetes Sci Technol. (2011) 5:212-24. doi: $10.1177 / 193229681100500202$

57. Awake brain surgery. Mayo Clinic. Available online at: https://www. mayoclinic.org/tests-procedures/awake-brain-surgery/about/pac-20384913 (accessed March 21, 2021).

58. Albani G, Cipresso P, Gaggioli A, Serino S, Vigna C, Priano L, et al. Virtual help for real surgery: the case of awake surgery. Stud Health Technol Inform. (2012) 173:13-5. doi: 10.3233/978-1-61499-022-2-13

59. Alsofy SZ, Nakamura M, Suleiman A, Sakellaropoulou I, Saravia HW, Shalamberidze D, et al. Cerebral anatomy detection and surgical planning in patients with anterior skull base meningiomas using a virtual reality technique. J Clin Med. (2021) 10:681. doi: 10.3390/JCM10040681

60. Wang S, Ying J, Wei L, Li S, Jing J. Guidance value of intracranial venous circulation evaluation to parasagittal meningioma operation. Int J Clin Exp Med. (2015) 8:13508.

61. Tang H-L, Sun H-P, Gong Y, Mao Y, Wu J-S, Zhang X-L, et al. Preoperative surgical planning for intracranial meningioma resection by virtual reality. Chin Med J (Engl). (2012) 125:2057-61. doi: 10.3760/cma.j.issn.0336-6999.2012.11.038

62. Ma S, Chen S, Hu Y, Qi J, Li Z, Cun E, et al. [Application of virtual reality system for individualized preoperative planning of sphenoidal ridge meningioma]. Zhonghua Yi Xue Za Zhi. (2014) 94:3562-6. doi: 10.3760/cma.j.issn.0376-2491.2014.45.007

63. Wang $S$, Zhang S, Jing J. Stereoscopic virtual reality models for planning tumor resection in the sellar region. BMC Neurol. (2012) 12:146. doi: 10.1186/1471-2377-12-146

64. Zawy Alsofy S, Sakellaropoulou I, Stroop R. Evaluation of surgical approaches for tumor resection in the deep infratentorial region and impact of virtual reality technique for the surgical planning and strategy. J Craniofac Surg. (2020) 31:1855-6. doi: 10.1097/SCS.0000000000006525

65. Tel A, Bagatto D, Tuniz F, Sembronio S, Costa F, D’Agostini S, et al. The evolution of craniofacial resection: a new workflow for virtual planning in complex craniofacial procedures. J Craniomaxillofac Surg. (2019) 47:147583. doi: 10.1016/J.JCMS.2019.06.016

66. Bradley D, Willson T, Chang JB, Gandolfi B, Zhu TR, Bradley JP, et al. Intraoperative three-dimensional virtual reality and computed tomographic guidance in temporomandibular joint arthroplasty of syndromic craniofacial dysostoses. Plastic Reconstr Surg Glob Open. (2019) 7:e2388. doi: 10.1097/GOX.0000000000002388

67. Jean WC, Tai AX, Hogan E, Herur-Raman A, Felbaum DR, Leonardo J, et al. An anatomical study of the foramen of Monro: implications in management of pineal tumors presenting with hydrocephalus. Acta Neurochir. (2019) 161:975-83. doi: 10.1007/S00701-019-03887-4

68. Mo D-p, Bao S-d, Li L, Yi Z-q, Zhang J-y, Zhang Y. Virtual reality system for diagnosis and therapeutic planning of cerebral aneurysms. Chin Med J (Engl). (2010) 123:2206-10. doi: 10.3760/cma.j.issn.0366-6999.2010.16.009

69. Zawy Alsofy S, Sakellaropoulou I, Nakamura M, Ewelt C, Salma A, Lewitz $\mathrm{M}$, et al. Impact of virtual reality in arterial anatomy detection and surgical planning in patients with unruptured anterior communicating artery aneurysms. Brain Sci. (2020) 10:1-16. doi: 10.3390/BRAINSCI10120963
70. Stadie AT, Kockro RA, Serra L, Fischer G, Schwandt E, Grunert P, et al. Neurosurgical craniotomy localization using a virtual reality planning system versus intraoperative image-guided navigation. Int J Comput Assist Radiol Surg. (2011) 6:565-72. doi: 10.1007/S11548-010-0529-1

71. Yi Z, He B, Deng Z, Liu Y, Huang S, Hong W. A virtual realitybased data analysis for optimizing freehand external ventricular drain insertion. Int J Comput Assist Radiol Surg. (2021) 16:269-76. doi: 10.1007/S11548-020-02277-X

72. Donofrio CA, Riccio L, Capitanio JF, Herur-Raman A, Panni P, Gagliardi F, et al. Transcortical endoportal subchoroidal endoscope-assisted approach to the third ventricle: from virtual reality to anatomical laboratory. J Neurosurg Sci. (2020) doi: 10.23736/S0390-5616.20.05122-X. [Epub ahead of print].

73. Shen M, Zhang X-L, Yang D-L, Wu J-S. Stereoscopic virtual reality presurgical planning for cerebrospinal otorrhea. Neurosciences (Riyadh). (2010) 15:204-8. doi: 10.3233/978-1-61499-595-1-192

74. Tai AX, Knudson K, Jean WC. Retrocondylar Far-Lateral Approach for Resection of a Craniocervical Junction Hemangioblastoma. J Neurol Surg B Skull Base. (2019) 80:S349-51. doi: 10.1055/S-0039-1698821

75. Du ZY, Gao X, Zhang XL, Wang ZQ, Tang WJ. Preoperative evaluation of neurovascular relationships for microvascular decompression in the cerebellopontine angle in a virtual reality environment. J Neurosurg. (2010) 113:479-85. doi: 10.3171/2009.9.JNS091012

76. Zawy Alsofy S, Nakamura M, Ewelt C, Kafchitsas K, Lewitz M, Schipmann $S$, et al. Retrospective comparison of minimally invasive and open monosegmental lumbar fusion, and impact of virtual reality on surgical planning and strategy. J Neurol Surg A Cent Eur Neurosurg. (2021) 82:399409. doi: 10.1055/S-0040-1719099

77. Zawy Alsofy S, Stroop R, Fusek I, Welzel Saravia H, Sakellaropoulou I, Yavuz M, et al. Virtual Reality-Based Evaluation of Surgical Planning and Outcome of Monosegmental, Unilateral Cervical Foraminal Stenosis. World Neurosurg. (2019) 129:e857-65. doi: 10.1016/J.WNEU.2019.06.057

78. Zawy Alsofy S, Nakamura M, Ewelt C, Kafchitsas K, Fortmann T, Schipmann S, et al. Comparison of stand-alone cage and cage-withplate for monosegmental cervical fusion and impact of virtual reality in evaluating surgical results. Clin Neurol Neurosurg. (2020) 191:105685. doi: 10.1016/J.CLINEURO.2020.105685

79. Keefe FJ, Huling DA, Coggins MJ, Keefe DF, Zachary Rosenthal M, Herr NR, et al. Virtual reality for persistent pain: a new direction for behavioral pain management. Pain. (2012) 153:2163-6. doi: 10.1016/j.pain.2012.05.030

80. Sharar SR, Carrougher GJ, Nakamura D, Hoffman HG, Blough DK, Patterson DR. factors influencing the efficacy of virtual reality distraction analgesia during postburn physical therapy: preliminary results from 3 ongoing studies. Arch Phys Med Rehabil. (2007) 88:S43-49. doi: 10.1016/j.apmr.2007.09.004

81. De Tommaso M, Ricci K, Laneve L, Savino N, Antonaci V, Livrea P. Virtual visual effect of hospital waiting room on pain modulation in healthy subjects and patients with chronic migraine. Pain Res Treat. (2013) 2013:515730. doi: 10.1155/2013/515730

82. Tejera DM, Beltran-Alacreu H, Cano-De-la-cuerda R, Hernández JVL, Martín-Pintado-zugasti A, Calvo-Lobo C, et al. Effects of virtual reality versus exercise on pain, functional, somatosensory and psychosocial outcomes in patients with non-specific chronic neck pain: a randomized clinical trial. Int J Environ Res Public Health. (2020) 17:1-19. doi: 10.3390/ijerph17165950

83. Harvie DS, Smith RT, Moseley GL, Meulders A, Michiels B, Sterling M. Illusion-enhanced virtual reality exercise for neck pain: a replicated single case series. Clin J Pain. (2020) 36:101-9. doi: 10.1097/AJP.00000000000 00780

84. Garcia L, Darnall B, Krishnamurthy P, Mackey I, Sackman J, Louis R, et al. Self-administered behavioral skills-Based at-home virtual reality therapy for chronic low back pain: protocol for a randomized controlled trial. JMIR Res Protoc. (2021) 10:e25291. doi: 10.2196/25291

85. Alemanno F, Houdayer E, Emedoli D, Locatelli M, Mortini P, Mandelli C, et al. Efficacy of virtual reality to reduce chronic low back pain: proofof-concept of a nonpharmacological approach on pain, quality of life, neuropsychological and functional outcome. PLoS ONE. (2019) 14:e0216858. doi: 10.1371/journal.pone.0216858 
86. Wang W en, Ho RLM, Gatto B, van der Veen SM, Underation MK, Thomas JS, et al. Cortical dynamics of movement-evoked pain in chronic low back pain. J Physiol. (2021) 599:289-305. doi: 10.1113/JP280735

87. Pozeg $\mathrm{P}$, Palluel E, Ronchi R, Solcà M, Al-Khodairy AW, Jordan $\mathrm{X}$, et al. Virtual reality improves embodiment and neuropathic pain caused by spinal cord injury. Neurology. (2017) 89:1894-903. doi: 10.1212/WNL.0000000000004585

88. Limakatso K, Parker R. Treatment recommendations for phantom limb pain in people with amputations: an expert consensus Delphi study. PM R. (2021) 13:1216-26. doi: 10.1002/pmrj.12556

89. La Paglia F, La Cascia C, Rizzo R, Sideli L, Francomano A, La Barbera D. Cognitive rehabilitation of schizophrenia through neurovr training. Ann Rev Cyber Therapy Telemed. (2013) 11:158-62. doi: 10.3233/978-1-61499-282-0-158

90. Rus-Calafell M, Garety P, Ward T, Williams G, Huckvale M, Leff J, et al. Confronting auditory hallucinations using virtual reality: the avatar therapy. Ann Rev Cyber Therapy Telemed. (2015) 13:192-196.

91. Canty AL, Neumann DL, Shum DHK. Using virtual reality to assess theory of mind subprocesses and error types in early and chronic schizophrenia. Schizophrenia Res. (2017) 10:15-9. doi: 10.1016/j.scog.2017.09.001

92. Moraes TM, de Andrade AF, Paiva WS. Virtual reality for the treatment of posttraumatic disorders. Neuropsychiatr Dis Treat. (2016) 12:785-6. doi: 10.2147/NDT.S105538

93. Dibbets P, Schulte-Ostermann MA. Virtual reality, real emotions: a novel analogue for the assessment of risk factors of post-traumatic stress disorder. Front Psychol. (2015) 6:681. doi: 10.3389/fpsyg.2015.00681

94. Schreurs BG, Burhans LB. Eyeblink classical conditioning and posttraumatic stress disorder - a model systems approach. Front Psychiatry. (2015) 6:50. doi: 10.3389/fpsyt.2015.00050

95. Difede J, Rothbaum BO, Rizzo AA, Wyka K, Spielman L, Jovanovic T, et al. Enhanced exposure therapy for combat-related posttraumatic stress disorder (PTSD): study protocol for a randomized controlled trial. Contemp Clin Trials. (2019) 87:105857. doi: 10.1016/j.cct.2019.105857

96. Bellani M, Fornasari L, Chittaro L, Brambilla P. Virtual reality in autism: state of the art. Epidemiol Psychiatr Sci. (2011) 20:235-8. doi: 10.1017/S2045796011000448

97. Maskey M, Rodgers J, Ingham B, Freeston M, Evans G, Labus M, et al. Using virtual reality environments to augment cognitive behavioral therapy for fears and phobias in autistic adults. Autism Adulthood. (2019) 1:134-45. doi: 10.1089/aut.2018.0019

98. Maskey M, Rodgers J, Grahame V, Glod M, Honey E, Kinnear J, et al. A randomised controlled feasibility trial of immersive virtual reality treatment with cognitive behaviour therapy for specific phobias in young people with autism spectrum disorder. J Autism Dev Disord. (2019) 49:1912-27. doi: 10.1007/s10803-018-3861-x

99. Maskey M, Lowry J, Rodgers J, McConachie H, Parr JR. Reducing specific phobia/fear in young people with autism spectrum disorders (ASDs) through a virtual reality environment intervention. PLoS ONE. (2014) 9:100374. doi: 10.1371/journal.pone.0100374

100. Cook J, Swapp D, Pan X, Bianchi-Berthouze N, Blakemore SJ. Atypical interference effect of action observation in autism spectrum conditions. Psychol Med. (2014) 44:731-40. doi: 10.1017/S00332917130 01335

101. Dechsling A, Shic F, Zhang D, Marschik PB, Esposito G, Orm S, et al. Virtual reality and naturalistic developmental behavioral interventions for children with autism spectrum disorder. Res Dev Disabil. (2021) 111:103885. doi: 10.1016/j.ridd.2021.103885

102. Lindner P, Miloff A, Bergman C, Andersson G, Hamilton W, Carlbring P. Gamified, automated virtual reality exposure therapy for fear of spiders: a single-subject trial under simulated real-world conditions. Front Psychiatry. (2020) 11:116. doi: 10.3389/fpsyt.2020.00116

103. Forbes PAG, Pan X, Antonia AF. Reduced mimicry to virtual reality avatars in autism spectrum disorder. J Autism Dev Disord. (2016) 46:3788-97. doi: 10.1007/s10803-016-2930-2

104. Lindner P, Rozental A, Jurell A, Reuterskiöld L, Andersson G, Hamilton W, et al. Experiences of gamified and automated virtual reality exposure therapy for spider phobia: qualitative study. JMIR Serious Games. (2020) 8:e17807. doi: $10.2196 / 17807$
105. Dunsmoor JE, Ahs F, Zielinski DJ, LaBar KS. Extinction in multiple virtual reality contexts diminishes fear reinstatement in humans. Neurobiol Learn Mem. (2014) 113:157-64. doi: 10.1016/j.nlm.2014.02.010

106. Verger A, Malbos E, Reynaud E, Mallet P, Mestre D, Pergandi JM, et al. Brain metabolism and related connectivity in patients with acrophobia treated by virtual reality therapy: an 18F-FDG PET pilot study sensitized by virtual exposure. EJNMMI Res. (2018) 8:93. doi: 10.1186/s13550-018-0446-9

107. Mosig C, Merz CJ, Mohr C, Adolph D, Wolf OT, Schneider S, et al. Enhanced discriminative fear learning of phobia-irrelevant stimuli in spider-fearful individuals. Front Behav Neurosci. (2014) 8:328. doi: 10.3389/fnbeh.2014.00328

108. Miloff A, Lindner P, Dafgård P, Deak S, Garke M, Hamilton W, et al. Automated virtual reality exposure therapy for spider phobia vs. in-vivo onesession treatment: a randomized non-inferiority trial. Behav Res Ther. (2019) 118:130-40. doi: 10.1016/j.brat.2019.04.004

109. Miloff A, Lindner P, Hamilton W, Reuterskiöld L, Andersson G, Carlbring P. Single-session gamified virtual reality exposure therapy for spider phobia vs. traditional exposure therapy: study protocol for a randomized controlled non-inferiority trial. Trials. (2016) 17:60. doi: 10.1186/s13063-016-1171-1

110. Gammeri R, Turri F, Ricci R, Ptak R. Adaptation to virtual prisms and its relevance for neglect rehabilitation: a single-blind dose-response study with healthy participants. Neuropsychol Rehabil. (2018) 30:753-766. doi: 10.1080/09602011.2018.1502672

111. Glize B, Lunven M, Rossetti Y, Revol P, Jacquin-Courtois S, Klinger E, et al. Improvement of navigation and representation in virtual reality after prism adaptation in neglect patients. Front Psychol. (2017) 8:2019. doi: 10.3389/FPSYG.2017.02019

112. Bourgeois A, Turri F, Schnider A, Ptak R. Virtual prism adaptation for spatial neglect: a double-blind study. Neuropsychol Rehabil. (2021) 31:1-15. doi: 10.1080/09602011.2020.1864412

113. Wåhlin A, Fordell H, Ekman U, Lenfeldt N, Malm J. Rehabilitation in chronic spatial neglect strengthens resting-state connectivity. Acta Neurol Scand. (2019) 139:254-9. doi: 10.1111/ANE.13048

114. Ekman U, Fordell H, Eriksson J, Lenfeldt N, Wåhlin A, Eklund A, et al. Increase of frontal neuronal activity in chronic neglect after training in virtual reality. Acta Neurol Scand. (2018) 138:284-92. doi: 10.1111/ANE.12955

115. Grimm F, Naros G, Gharabaghi A. Closed-loop task difficulty adaptation during virtual reality reach-to-grasp training assisted with an exoskeleton for stroke rehabilitation. Front Neurosci. (2016) 10:518. doi: 10.3389/FNINS.2016.00518

116. Grimm F, Naros G, Gharabaghi A. Compensation or restoration: closedloop feedback of movement quality for assisted reach-to-grasp exercises with a multi-joint arm exoskeleton. Front Neurosci. (2016) 10:280. doi: 10.3389/FNINS.2016.00280

117. Grimm F, Gharabaghi A. Closed-loop neuroprosthesis for reach-to-grasp assistance: combining adaptive multi-channel neuromuscular stimulation with a multi-joint arm exoskeleton. Front Neurosci. (2016) 10:284. doi: 10.3389/FNINS.2016.00284

118. Hussain N, Alt Murphy M, Sunnerhagen KS. Upper limb kinematics in stroke and healthy controls using target-to-target task in virtual reality. Front Neurol. (2018) 10:300. doi: 10.3389/FNEUR.2018.00300

119. Kiper P, Szczudlik A, Agostini M, Opara J, Nowobilski R, Ventura L, et al. Virtual reality for upper limb rehabilitation in subacute and chronic stroke: a randomized controlled trial. Arch Phys Med Rehabil. (2018) 99:834-842.e4. doi: 10.1016/J.APMR.2018.01.023

120. Zakharov AV, Bulanov VA, Khivintseva EV, Kolsanov AV, Bushkova YV, Ivanova GE. Stroke affected lower limbs rehabilitation combining virtual reality with tactile feedback. Front Robot AI. (2020) 7:81. doi: 10.3389/FROBT.2020.00081

121. Mekbib DB, Debeli DK, Zhang L, Fang S, Shao Y, Yang W, et al. A novel fully immersive virtual reality environment for upper extremity rehabilitation in patients with stroke. Ann N Y Acad Sci. (2021) 1493:75-89. doi: 10.1111/NYAS.14554

122. Mekbib DB, Zhao Z, Wang J, Xu B, Zhang L, Cheng R, et al. Proactive motor functional recovery following immersive virtual reality-based limb mirroring therapy in patients with subacute stroke. Neurotherapeutics. (2020) 17:191930. doi: $10.1007 / \mathrm{S} 13311-020-00882-\mathrm{X}$ 
123. Johansson BB. Multisensory Stimulation in Stroke Rehabilitation. Front Hum Neurosci. (2012) 6:60. doi: 10.3389/FNHUM.2012.00060

124. Samuel GS, Oey NE, Choo M, Ju H, Chan WY, Kok S, et al. Combining levodopa and virtual reality-based therapy for rehabilitation of the upper limb after acute stroke: pilot study Part II. Singapore Med J. (2017) 58:610617. doi: 10.11622/SMEDJ.2016111

125. Iosa M, Aydin M, Candelise C, Coda N, Morone G, Antonucci G, et al. The michelangelo effect: art improves the performance in a virtual reality task developed for upper limb neurorehabilitation. Front Psychol. (2021) 11:3832. doi: 10.3389/FPSYG.2020.611956

126. Erhardsson M, Alt Murphy M, Sunnerhagen KS. Commercial headmounted display virtual reality for upper extremity rehabilitation in chronic stroke: a single-case design study. J Neuroeng Rehabil. (2020) 17:154. doi: 10.1186/S12984-020-00788-X

127. Kilbride C, Scott DJM, Butcher T, Norris M, Ryan JM, Anokye N, et al. Rehabilitation via HOMe Based gaming exercise for the Upper-limb post Stroke (RHOMBUS): protocol of an intervention feasibility trial. BMJ Open. (2018) 8:e026620. doi: 10.1136/BMJOPEN-2018-026620

128. McNulty PA. Games for rehabilitation: wii-based movement therapy improves poststroke movement ability. Games Health J. (2012) 1:384-7. doi: 10.1089/G4H.2012.0055

129. Carregosa AA, Aguiar Dos Santos LR, Masruha MR, Coêlho MLDS, Machado TC, Souza DCB, et al. Virtual rehabilitation through nintendo wii in poststroke patients: follow-up. J Stroke Cerebrovasc Dis. (2018) 27:494-8. doi: 10.1016/J.JSTROKECEREBROVASDIS.2017.09.029

130. Verschure PF. Neuroscience, virtual reality and neurorehabilitation: brain repair as a validation of brain theory. Ann Int Conf IEEE Eng Med Bio Soc. (2011) 2011:2254-7. doi: 10.1109/IEMBS.2011.6090428

131. Zanona AF, de Souza RF, Aidar FJ, de Matos DG, Santos KMB, Paixão $\mathrm{MDC}$, et al. Use of virtual rehabilitation to improve the symmetry of body temperature, balance, and functionality of patients with stroke sequelae. Ann Neurosci. (2019) 25:166-73. doi: 10.1159/000488581

132. Munari D, Fonte C, Varalta V, Battistuzzi E, Cassini S, Montagnoli AP, et al. Effects of robot-assisted gait training combined with virtual reality on motor and cognitive functions in patients with multiple sclerosis: a pilot, singleblind, randomized controlled trial. Restor Neurol Neurosci. (2020) 38:151-4. doi: 10.3233/RNN-190974

133. Hsieh KL, Mirelman A, Shema-Shiratzky S, Galperin I, Regev K, Shen S, et al. A multi-modal virtual reality treadmill intervention for enhancing mobility and cognitive function in people with multiple sclerosis: protocol for a randomized controlled trial. Contemp Clin Trials. (2020) 97:106122. doi: 10.1016/J.CCT.2020.106122

134. Al-Sharman A, Khalil H, El-Salem K, Alghwiri AA, Khazaaleh S, Khraim M. Motor performance improvement through virtual reality task is related to fatigue and cognition in people with multiple sclerosis. Physiother Res Int. (2019) 24:e1782 doi: 10.1002/PRI.1782

135. Sengupta M, Gupta A, Khanna M, Rashmi Krishnan UK, Chakrabarti D. Role of virtual reality in balance training in patients with spinal cord injury: a prospective comparative pre-post study. Asian Spine J. (2020) 14:51-58. doi: 10.31616/ASJ.2019.0013

136. Harvie DS, Smith RT, Hunter EV, Davis MG, Sterling M, Moseley GL. Using visuo-kinetic virtual reality to induce illusory spinal movement: the MoOVi Illusion. PeerJ. (2017) 5:1-16. doi: 10.7717/PEERJ.3023

137. Doniger GM, Beeri MS, Bahar-Fuchs A, Gottlieb A, Tkachov A, Kenan $\mathrm{H}$, et al. Virtual reality-based cognitive-motor training for middle-aged adults at high Alzheimer's disease risk: a randomized controlled trial. Alzheimers Dementia (N Y). (2018) 4:118-29. doi: 10.1016/J.TRCI.2018. 02.005

138. Shema SR, Brozgol M, Dorfman M, Maidan I, Sharaby-Yeshayahu L, MalikKozuch H, et al. Clinical experience using a 5-week treadmill training program with virtual reality to enhance gait in an ambulatory physical therapy service. Phys Ther. (2014) 94:1319-26. doi: 10.2522/PTJ.20130305

139. Summa S, Gori R, Freda L, Castelli E, Petrarca M. Development of a dynamic oriented rehabilitative integrated system (DORIS) and preliminary tests. Sensors. (2019) 19:3402. doi: 10.3390/S19153402

140. Sadeghi H, Jehu DA, Daneshjoo A, Shakoor E, Razeghi M, Amani A, et al. Effects of 8 weeks of balance training, virtual reality training, and combined exercise on lower limb muscle strength, balance, and functional mobility among older men: a randomized controlled trial. Sports Health. (2021) 13:606-12. doi: 10.1177/1941738120986803

141. Ettenhofer ML, Guise B, Brandler B, Bittner K, Gimbel SI, Cordero E, et al. Neurocognitive driving rehabilitation in virtual environments (NeuroDRIVE): a pilot clinical trial for chronic traumatic brain injury. Neurorehabilitation. (2019) 44:531-44. doi: 10.3233/NRE-192718

142. Gimbel SI, Ettenhofer ML, Cordero E, Roy M, Chan L. Brain bases of recovery following cognitive rehabilitation for traumatic brain injury: a preliminary study. Brain Imaging Behav. (2021) 15:410-20. doi: 10.1007/S11682-020-00269-8

143. Williams L, Jackson CP, Choe N, Pelland L, Scott SH, Reynolds JN. Sensorymotor deficits in children with fetal alcohol spectrum disorder assessed using a robotic virtual reality platform. Alcohol Clin Exp Res. (2014) 38:116-25. doi: 10.1111/ACER.12225

144. Coco-Martin MB, Piñero DP, Leal-Vega L, Hernández-Rodríguez CJ, Adiego J, Molina-Martín A, et al. The potential of virtual reality for inducing neuroplasticity in children with amblyopia. J Ophthalmol. (2020) 2020:7067846. doi: 10.1155/2020/7067846

145. Vedamurthy I, Knill DC, Huang SJ, Yung A, Ding J, Kwon OS, et al. Recovering stereo vision by squashing virtual bugs in a virtual reality environment. Philos Trans R Soc Lond B Biol Sci. (2016) 371:20150264. doi: 10.1098/RSTB.2015.0264

146. McNish RN, Chembrammel P, Speidel NC, Lin JJ, López-Ortiz C. Rehabilitation for children with dystonic cerebral palsy using haptic feedback in virtual reality: protocol for a randomized controlled trial. JMIR Res Protoc. (2019) 8: 11470. doi: 10.2196/11470

147. Robert MT, Levin MF. Validation of reaching in a virtual environment in typically developing children and children with mild unilateral cerebral palsy. Dev Med Child Neurol. (2018) 60:382-90. doi: 10.1111/DMCN.13688

148. Lopes JBP, Grecco LAC, Moura RCF, Lazzari RD, Duarte NAC, Miziara I, et al. Protocol study for a randomised, controlled, doubleblind, clinical trial involving virtual reality and anodal transcranial direct current stimulation for the improvement of upper limb motor function in children with Down syndrome. BMJ Open. (2017) 7:e016260. doi: 10.1136/BMJOPEN-2017-016260

149. Collange Grecco LA, de Almeida Carvalho Duarte N, Mendonça ME, Galli M, Fregni F, Oliveira CS. Effects of anodal transcranial direct current stimulation combined with virtual reality for improving gait in children with spastic diparetic cerebral palsy: a pilot, randomized, controlled, double-blind, clinical trial. Clin Rehabil. (2015) 29:1212-23. doi: 10.1177/0269215514566997

150. Cánovas R, León I, Serrano P, Roldán MD, Cimadevilla JM. Spatial navigation impairment in patients with refractory temporal lobe epilepsy: evidence from a new virtual reality-based task. Epilepsy Behav. (2011) 22:364-9. doi: 10.1016/J.YEBEH.2011.07.021

151. Canning CG, Allen NE, Nackaerts E, Paul SS, Nieuwboer A, Gilat M. Virtual reality in research and rehabilitation of gait and balance in Parkinson disease. Nat Rev Neurol. (2020) 16:409-25. doi: 10.1038/s41582-020-0370-2

152. Robles-García V, Arias P, Sanmartín G, Espinosa N, Flores J, Grieve KL, et al. Motor facilitation during real-time movement imitation in Parkinson's disease: a virtual reality study. Parkinsonism Relat Disord. (2013) 19:1123-9. doi: 10.1016/J.PARKRELDIS.2013.08.005

153. Robles-García V, Corral-Bergantiños Y, Espinosa N, García-Sancho C, Sanmartín G, Flores J, et al. Effects of movement imitation training in Parkinson's disease: a virtual reality pilot study. Parkinsonism Relat Disord. (2016) 26:17-23. doi: 10.1016/J.PARKRELDIS.2016. 02.022

154. Arias P, Robles-García V, Sanmartín G, Flores J, Cudeiro J. Virtual reality as a tool for evaluation of repetitive rhythmic movements in the elderly and Parkinson's disease patients. PLoS ONE. (2012) 7:e30021. doi: 10.1371/JOURNAL.PONE.0030021

155. Lheureux A, Lebleu J, Frisque C, Sion C, Stoquart G, Warlop T, et al. Immersive virtual reality to restore natural long-range autocorrelations in Parkinson's disease patients' gait during treadmill walking. Front Physiol. (2020) 11:1207. doi: 10.3389/FPHYS.2020.572063

156. Maidan I, Rosenberg-Katz K, Jacob Y, Giladi N, Hausdorff JM, Mirelman A. Disparate effects of training on brain activation in Parkinson disease. Neurology. (2017) 89:1804-10. doi: 10.1212/WNL.0000000000004576 
157. Droby A, Maidan I, Jacob Y, Giladi N, Hausdorff JM, Mirelman A. Distinct effects of motor training on resting-state functional networks of the brain in Parkinson's disease. Neurorehabil Neural Repair. (2020) 34:795-803. doi: 10.1177/1545968320940985

158. Pelosin E, Cerulli C, Ogliastro C, Lagravinese G, Mori L, Bonassi G, et al. A multimodal training modulates short afferent inhibition and improves complex walking in a cohort of faller older adults with an increased prevalence of Parkinson's disease. J Gerontol A Biol Sci Med Sci. (2020) 75:722-8. doi: 10.1093/GERONA/GLZ072

159. Georgiades MJ, Gilat M, Ehgoetz Martens KA, Walton CC, Bissett PG, Shine JM, et al. Investigating motor initiation and inhibition deficits in patients with Parkinson's disease and freezing of gait using a virtual reality paradigm. Neuroscience. (2016) 337:153-62. doi: 10.1016/J.NEUROSCIENCE.2016.09.019

160. Griffin HJ, Greenlaw R, Limousin P, Bhatia K, Quinn NP, Jahanshahi M. The effect of real and virtual visual cues on walking in Parkinson's disease. J Neurol. (2011) 258:991-1000. doi: 10.1007/S00415-0105866-Z

161. Finley JM, Gotsis M, Lympouridis V, Jain S, Kim A, Fisher BE. Design and development of a virtual reality-based mobility training game for people with Parkinson's disease. Front Neurol. (2021) 11:1692. doi: 10.3389/FNEUR.2020.577713

162. Santos P, Machado T, Santos L, Ribeiro N, Melo A. Efficacy of the nintendo wii combination with conventional exercises in the rehabilitation of individuals with parkinson's disease: a randomized clinical trial. Neurorehabilitation. (2019) 45:255-63. doi: 10.3233/NRE-1 92771

163. Pazzaglia C, Imbimbo I, Tranchita E, Minganti C, Ricciardi D, lo Monaco $\mathrm{R}$, et al. Comparison of virtual reality rehabilitation and conventional rehabilitation in Parkinson's disease: a randomised controlled trial. Physiotherapy. (2020) 106:36-42. doi: 10.1016/J.PHYSIO.2019.12.007

164. Kourtesis P, Collina S, Doumas LAA, MacPherson SE. Technological competence is a pre-condition for effective implementation of virtual reality head mounted displays in human neuroscience: a technological review and meta-analysis. Front Hum Neurosci. (2019) 13:342. doi: 10.3389/fnhum.2019.00342

165. Maddahi Y, Zareinia K, Tomanek B, Sutherland GR. Challenges in developing a magnetic resonance-compatible haptic hand-controller for neurosurgical training. Proc Inst Mech Eng H. (2018) 232:1148-67. doi: $10.1177 / 0954411918806934$
166. Tychsen L, Thio LL. Concern of photosensitive seizures evoked by $3 \mathrm{D}$ video displays or virtual reality headsets in children: current perspective. Eye Brain. (2020) 12:45-8. doi: 10.2147/EB.S233195

167. Kellmeyer P, Biller-Andorno N, Meynen G. Ethical tensions of virtual reality treatment in vulnerable patients. Nat Med. (2019) 25:1185-8. doi: 10.1038/s41591-019-0543-y

168. Riches S, Elghany S, Garety P, Rus-Calafell M, Valmaggia L. Factors affecting sense of presence in a virtual reality social environment: a qualitative study. Cyberpsychol Behav Soc Network. (2019) 22:288-92. doi: 10.1089/cyber.2018.0128

169. Somrak A, Pogačnik M, Guna J. Suitability and comparison of questionnaires assessing virtual reality-induced symptoms and effects and user experience in virtual environments. Sensors (Switzerland). (2021) 21:1-24. doi: 10.3390/s21041185

170. Albani G, Pedroli E, Cipresso P, Bulla D, Cimolin V, Thomas A, et al. Visual hallucinations as incidental negative effects of virtual reality on Parkinson's disease patients: a link with neurodegeneration? Parkinsons Dis. (2015) 2015:194629. doi: 10.1155/2015/194629

171. Jean WC, Britz GW, DiMeco F, Elmi-Terander A, McIntyre C. Introduction. Virtual and augmented reality in neurosurgery: a timeline. Neurosurg Focus. (2021) 51:E1. doi: 10.3171/2021.5.FOCUS21313

Conflict of Interest: The authors declare that the research was conducted in the absence of any commercial or financial relationships that could be construed as a potential conflict of interest.

Publisher's Note: All claims expressed in this article are solely those of the authors and do not necessarily represent those of their affiliated organizations, or those of the publisher, the editors and the reviewers. Any product that may be evaluated in this article, or claim that may be made by its manufacturer, is not guaranteed or endorsed by the publisher.

Copyright (C) 2022 Scott, Griffin, Coggins, Elberson, Abdeldayem, Virmani, LarsonPrior and Petersen. This is an open-access article distributed under the terms of the Creative Commons Attribution License (CC BY). The use, distribution or reproduction in other forums is permitted, provided the original author(s) and the copyright owner(s) are credited and that the original publication in this journal is cited, in accordance with accepted academic practice. No use, distribution or reproduction is permitted which does not comply with these terms. 